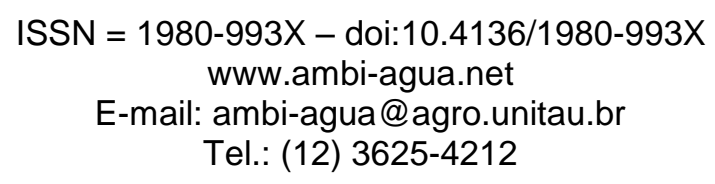

\title{
Modelagem para integração de dados sobre macrobentos em Infraestrutura de Dados Espaciais
}

\author{
(http://dx.doi.org/10.4136/ambi-agua.774)
}

\section{Gabriel Niero de Carvalho ${ }^{1}$; Mariana Abrantes Giannotti ${ }^{2}$; Silvia Sartor ${ }^{3}$;José Alberto Quintanilha ${ }^{4}$}

\author{
Escola Politécnica da Universidade de São Paulo - \\ Depto. Engenharia de Transportes - Laboratório de Geoprocessamento (LGP). \\ e-mails: ${ }^{1}$ gabrielncarvalho@ hotmail.com, ${ }^{2}$ mariana.giannotti@gmail.com, \\ ${ }^{3}$ ssartor@uol.com.br, ${ }^{4}$ jaquinta@usp.br
}

\section{RESUMO}

As Zonas Costeiras são áreas complexas que contemplam ambientes terrestres e marinhos que, além de possuírem enorme riqueza ambiental, também são áreas atrativas aos seres humanos por oferecer alimentos, lazer, negócios, transporte, entre outros. Algumas dificuldades de gerenciamento ocorrem pela complexidade, conflito de interesses e pelo fato de não haver padronização no levantamento de dados e disponibilização para a comunidade científica, órgãos públicos, etc. A organização, padronização e compartilhamento destas informações em Atlas Web são essenciais para auxiliar no planejamento e tomada de decisão pois agregam, em um único ambiente, diversos dados provenientes de fontes distintas. A construção de um modelo de dados espacial voltado à área ambiental, para ser utilizada em Infraestrutura de Dados Espaciais (IDE) é exemplificada a partir da modelagem de um bioindicador de qualidade de sedimentos. Este trabalho apresenta as etapas necessárias para a construção de modelo de dados espacial de Macrobentos e emprega a Região Metropolitana da Baixada Santista como referência. Conclui-se que a estruturação do conhecimento quando se trabalha com dados ambientais em um modelo é essencial para sua posterior integração em IDE. Constatou-se no processo de modelagem que questões metodológicas relativas ao processo de coleta podem dificultar ou inviabilizar a integração de dados provenientes de diferentes estudos em uma mesma área. A construção de um modelo de dados espacial, como o apresentado neste estudo poderá ser utilizado como referência para novas pesquisas com objetivos semelhantes.

Palavras-chave: IDE, Baixada Santista, SIG; biomonitoramento, Macrobentos, Modelo de Dados Espaciais.

\section{Database modeling to integrate macrobenthos data in Spatial Data Infrastructure}

\section{ABSTRACT}

Coastal zones are complex areas that include marine and terrestrial environments. Besides its huge environmental wealth, they also attracts humans because provides food, recreation, business, and transportation, among others. Some difficulties to manage these areas are related with their complexity, diversity of interests and the absence of standardization to collect and share data to scientific community, public agencies, among others. The idea to organize, standardize and share this information based on Web Atlas is 
essential to support planning and decision making issues. The construction of a spatial database integrating the environmental business, to be used on Spatial Data Infrastructure (SDI) is illustrated by a bioindicator that indicates the quality of the sediments. The models show the phases required to build Macrobenthos spatial database based on Santos Metropolitan Region as a reference. It is concluded that, when working with environmental data the structuring of knowledge in a conceptual model is essential for their subsequent integration into the SDI. During the modeling process it can be noticed that methodological issues related to the collection process may obstruct or prejudice the integration of data from different studies of the same area. The development of a database model, as presented in this study, can be used as a reference for further research with similar goals.

Keywords: SDI, GIS, Macrobenthos, biomonitoring, Spatial Database Model.

\section{INTRODUÇÃO}

A importância em zonas costeiras e marinhas aumenta significativamente pela concentração populacional, aspecto político, social e econômico envolvidos. Small e Cohen, (2004) descrevem sobre a distribuição espacial da população humana no mundo e ressaltam sua concentração em zonas costeiras.

A informação geográfica em zonas costeiras é essencial, pois agrega o contexto espacial, o que permite a realização de análises. Estas indicam distribuição, concentração e tendências de indicadores ambientais que facilitam o planejamento costeiro. Entretanto, para se fazer uso deste potencial é imprescindível que as fontes de dados sigam normas para que possam ser compartilhadas.

As iniciativas de organização e compartilhamento de informações costeiras, principalmente as internacionais (Estados Unidos, Canadá, Irlanda, Reino Unido e Austrália), estão em processo de desenvolvimento e cada vez mais buscam construir uma ferramenta que possa auxiliar na gestão e na tomada de decisão, por meio da integração de dados e a sua rápida disponibilização por meio, por exemplo, de portais.

No Brasil as iniciativas para construção de Infraestruturas de Dados Espaciais (IDEs) que contemplem as questões Costeiras e Marinhas ainda são incipientes. As Cartas de Sensibilidade Ambiental ao Óleo desenvolvidas pela Petrobras (Araujo et al., 2007) e pelo Ministério do Meio Ambiente Brasileiro (Ghehardi et al., 2008), avançaram na questão, mas não tratam de aspectos relativos à padronização no levantamento de dados ambientais e disponibilização ampla para facilitar o planejamento costeiro.

A proposta deste artigo é propor as etapas necessárias para a construção de um modelo de dados espacial com enfoque ambiental. $\mathrm{O}$ estudo focou no tema macrobentos, a partir de fontes de dados distintas e sem padrão de codificação dos levantamentos, para serem disponibilizadas e consumidas de forma padronizada por meio de um Atlas Web baseado em IDE. A área escolhida para a construção do modelo de dados foi a Região Metropolitana da Baixada Santista (RMBS), por ser relevante sob diversos aspectos ambientais e socioeconômicos (Sartor et al., 2007, 2009). Trata-se, portanto, de uma forma estruturada de representar os dados que, posteriormente, pode ser estendida para outras regiões e/ou temas ambientais.

Este trabalho está estruturado do seguinte modo: além desta Introdução, o item 2 apresenta uma revisão sobre IDEs para gerenciamento costeiro e marinho; o item 3 descreve a área de estudos e a importância dos macrobentos. No item 4 estão descritos os materiais e métodos utilizados, o quinto item apresenta os resultados e uma discussão e as conclusões são apresentadas no item 6 . 


\section{Infraestrutura de dados espaciais para gerenciamento costeiro e marinho}

Strain et al. (2004), Rajabifard et al. (2008) e Bartlett e Smith (2005) ilustram dificuldades encontradas no gerenciamento de zonas costeiras:

- São governadas por complexas legislações e instituições;

- Agências governamentais em âmbito regional ou nacional são responsáveis por diferentes aspectos da mesma área física e uso da zona costeira, como por exemplo: meio ambiente, pesca, agricultura, transporte, planejamento urbano e cadastro;

- As mudanças do ambiente marinho são muito mais rápidas em relação ao ambiente terrestre;

- Há menos levantamento de dados e estudos que em ambiente terrestre.

Além dos aspectos apresentados há dificuldade na coleta, gerenciamento $\mathrm{e}$ disponibilização de dados nesses ambientes. Strain et al. (2004), Rajabifard et al. (2008) e Bartlett e Smith (2005) explicitam, os seguintes fatores a destacar:

- Os dados são dinâmicos e multidimensionais dificultando a delimitação da área de coleta e a atualização dos dados;

- Os dados são coletados para um projeto específico e raramente são compartilhados com outras organizações;

- Não há padronização no levantamento de dados, dificultando assim, a interoperabilidade (troca de informações sem necessidade de transformação);

- As diferenças entre ambientes marinhos e terrestres, além dos métodos de coleta e tecnologias utilizadas para o levantamento de dados, representam grande desafio para a interoperabilidade entre ambos;

- Os estudos sobre políticas para dados espaciais marinhos ainda são incipientes.

A complexa relação entre diferentes tipos de informações espaciais e a enorme dificuldade em gerenciar áreas costeiras incentiva, de certa forma, que cada país ou organização defina diferentes rotinas para a construção de uma arquitetura que possibilite a integração de dados entre os interessados (Bartlett e Smith, 2005).

Diante deste contexto, a implementação de soluções como a IDEs tem como principal objetivo facilitar e coordenar a troca e o compartilhamento de dados e serviços espaciais para melhor atingir as diversas necessidades em diferentes níveis político e administrativo. (Hjelmager et al., 2008; Rajabifard et al., 2006).

O Global Spatial Data Infrastructure Association (GSDI) é uma associação que promove a cooperação internacional e colabora com a criação de IDEs em diferentes escalas, sendo também responsável em produzir o chamado GSDI Cookbook, espécie de guia para a implementação de um IDE (GSDI, 2004):

"O termo Infraestrutura de Dados Espaciais (IDE), é frequentemente usado para designar a coleção de tecnologias, políticas e arranjos institucionais que facilitem a viabilidade e o acesso aos dados geográficos. A IDE fornece uma base para a descoberta de dados geográficos, avaliação e aplicação para os usuários e provedores em todos os níveis de governo, setor comercial, setor sem fins lucrativos, universidades e cidadãos em geral."

Uma IDE é muito mais do que simplesmente um conjunto de amostras ou banco de dados e vai além do levantamento e mapeamento de dados; na prática fornece um ambiente na qual organizações/ nações interagem, via tecnologia, para promover o uso, gerenciamento e produção de mecanismos para busca, acesso à dados, além de serviços ou softwares que dão suporte a toda esta comunicação (GSDI, 2004; Rajabifard et al., 2006).

Inicialmente, as IDEs contavam com uma metodologia de modelagem orientada aos produtos que visava um escopo temático amplo, em uma estratégia de concepção baseada na estrutura top-down (Rajabifard et al., 2006). A partir das experiências dessa primeira geração, 
percebeu-se que esse modelo não mais satisfazia às necessidades preconizadas para uma IDE. Com a evolução para a segunda geração de IDE, a modelagem passou a ser orientada a processos e sua constituição contava com uma visão bottom-up, partindo de estruturas locais para a posterior formação de uma estrutura nacional (Rajabifard et al., 2006). Crompvoets et al. (2004) analisam experiências em vários países, descrevendo cada componente do IDE sob a perspectiva de cada iniciativa estudada, e reforçam a ideia dessa mudança de estratégia da primeira geração de IDEs, orientada aos produtos e dados, para a segunda geração, mais orientadas às aplicações e seus usuários.

Iniciativas que privilegiam os conhecimentos locais são valorizadas pela riqueza de aplicações e diversidade de interesses impondo novos requisitos às IDEs. Diferentemente das questões relativas às propostas de IDE nacionais, as propostas locais requerem um maior detalhamento e, com isso, um maior acesso a diferentes fontes de dados, mantidas por diversos provedores (Davis e Alves, 2005).

A tendência de popularização da utilização de dados geográficos, decorrente das facilidades promovidas pelos serviços disponibilizados pela Web, tem feito com que, recentemente, haja uma demanda convergente por modelos de Infraestruturas de Dados Espaciais locais orientadas a serviços (Davis e Alves, 2005; Vaccari et al., 2008). Chan et al. (2001) ao analisarem as diversas definições de IDE, já mencionavam a falta de uma perspectiva de serviços nessas definições.

Masser et al. (2008) mencionam que o desenvolvimento de Infraestruturas de Dados Espaciais efetivas deve servir de forma transparente como suporte para a vasta maioria da sociedade que não é familiarizada com conceitos sobre consultas espaciais. Essas estruturas devem ser aprimoradas de tal forma que seja possível compartilhar, adicionalmente aos dados, estratégias, processos, operações, produtos de valor agregado, dentre outros.

Especificamente na questão de gerenciamento costeiro e marinho, as diversas atividades internacionais referentes ao assunto ajudaram e subsidiaram o desenvolvimento de soluções para suportar e compartilhar a dimensão espacial de dados marinhos e costeiros, conforme Strain (2008).

Como também lembra USCoOP (2002): "há a necessidade por uma melhor e mais compreensiva maneira para agregar trabalhos provenientes de diferentes disciplinas com o objetivo de oferecer um entendimento mais integrado do meio ambiente marinho e os processos que o controla (...) há a necessidade de se padronizar práticas e procedimentos".

Diante deste contexto, alguns IDEs estão sendo desenvolvidos com o enfoque principal no gerenciamento do ambiente costeiro e marinho. Como é possível notar, os casos explicitados a seguir, normalmente fazem parte de um IDE em maior escala, seja este regional ou nacional, que demonstra a preocupação de não serem desenvolvidos de maneira isolada e seguem as melhores práticas internacionais de padronização, troca de dados, etc.:

Inverti todos: nome depois sigla. É convenção.

- Coastal Spatial Data Infrastructure (CSDI): é gerenciado pelo Centro de Serviços Costeiros (The National Oceanic and Atmospheric Administration - NOAA), sendo desenvolvido como parte do IDE Americano (US NSDI), que permitiu o acesso e consumo de dados geoespaciais costeiros e marinhos (NOAA, 2011);

- Marine Geospatial Data Infrastructure (MGDI), iniciado no ano de 1999, como parte integrante do Canadian Geospatial Data Initiative (CGDI), agora denominado GeoConnections (CGDI, 2011);

- Marine Environmental Data and Information Network (MEDIN) desenvolvido na Inglaterra, o projeto iniciou no ano de 2003 com o nome de Marine Data and Information Partnership (MDIP) e em 2008, mudou-se o nome do Órgão que gerenciava tal projeto Marine Science Coordination Committee (MSCC) e consequentemente a solução sofreu uma restruturação para o nome atual (MEDIN, 2011); 
- Marine Irish Data Atlas (MIDA): Segundo Strain (2008), a Irlanda possui uma significativa quantidade de dados relacionados com o ambiente costeiro e marinho, pela integração de 18 diferentes agências em 6 departamentos distintos do governo. O projeto MIDA tem como intuito melhorar o acesso aos dados espaciais por meio do desenvolvimento de um Atlas Marinho (MIDA, 2011);

- Há diversas iniciativas na Austrália, sendo a Australian Marine Boundary Information System (AMBIS), desenvolvido pelo Geoscience Australia (GA) no ano de 2001 (AMSIS, 2011) e o Australian Ocean Data Centre Joint Facility (AODCJF), inaugurado em 2005 (AODCJF, 2011);

- African Marine Atlas (AMA): projeto desenvolvido pela Ocean Data and Information Network for Africa (ODINAFRICA), responsável por organizar mais de 40 institutos marinhos em 25 países na África, oficialmente lançado em 23 de Fevereiro de 2007, contendo grande quantidade de geo-informação marinha referente ao litoral e oceano africanos (ODINAFRICA, 2011);

- International Coastal Atlas Network (ICAN): é uma iniciativa formada por um grupo informal que contém mais de 35 organizações, com representações na Europa, América e África. Um dos principais objetivos do grupo é compartilhar experiências e soluções comuns para auxiliar no desenvolvimento de Portais Web (Atlas Ambiental - IDEs), levando em consideração padrões de armazenamento de metadados e troca de informações espaciais (ICAN, 2011).

Portanto, um dado proveniente de um estudo ou levantamento específico para ser consumido dentro de um Atlas Web, seguindo os conceitos de uma IDE, deve passar por uma série de etapas até que tal dado se transforme em uma informação realmente útil a um usuário final que fará uso para a tomada de decisão. É neste sentido que será ilustrado no tópico abaixo as etapas necessárias para inserir estudos distintos, realizados sobre diferentes perspectivas e contexto, referentes ao tema Macrobentos, em um modelo único de banco de dados, seguindo regras e padrões, para posterior disponibilização em IDE.

\section{3. Área de estudo e importância de macrobentos}

A Zona Costeira é "o espaço delimitado pela interface entre o oceano e a terra, ou seja, a faixa terrestre que recebe influência marítima e a faixa marítima que recebe influência terrestre", que na prática, trata-se de uma área de interface entre o ar, terra e mar (Rodríguez e Windevoxhel, 1998). Segundo o Atlas Universal do Oceano (UN Atlas, 2011), estima-se que dois terços da população vivem a 60 quilômetros da costa e que o crescimento da população humana nestas regiões seja cerca do dobro em relação à outras áreas do mundo.

Nos estuários concentram-se grandes centros urbanos, intensa atividade industrial, portuária e comercial (Nybakken, 1995). Essas atividades implicam em potenciais impactos ambientais (Kennish, 1997; Rivero et al., 2005). O aumento da industrialização na área estudada insere uma grande quantidade de agentes tóxicos que se acumulam no sedimento e influenciam diretamente nas populações faunísticas que vivem nestas áreas. O impacto em um elo da cadeia trófica, no caso, o macrobentos, interfere na atividade pesqueira, por exemplo.

Biologicamente, os estuários estão entre os ecossistemas mais produtivos do oceano. A Baixada Santista, região que compreende a área estudada no presente artigo, conforme ilustra a Figura 1, engloba o sistema estuarino de Santos e São Vicente. Localiza-se na faixa litorânea do Estado de São Paulo e apresenta complexa estrutura de ocupação da zona costeira que, frequentemente implica em conflito com o equilíbrio dos ecossistemas. Com relação à contaminação química industrial e orgânica, o estuário de Santos é considerado uma área crítica (CETESB, 2001, 2004, 20072008 e 2009; Sartor e Degaspari, 2000). 


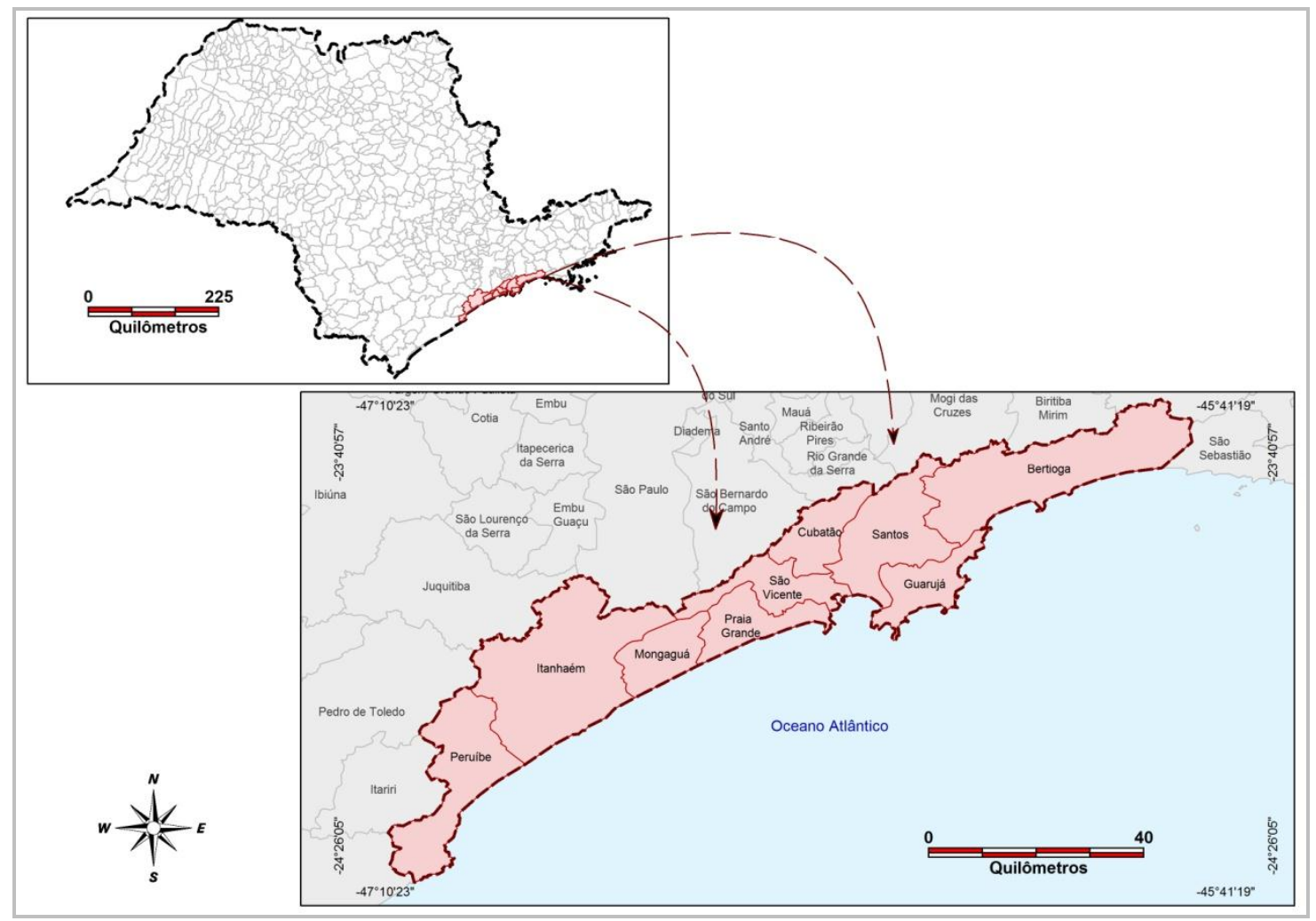

Figura 1. Contexto Espacial da Região Metropolitana da Baixada Santista no Estado de São Paulo composta pelos municípios: Bertioga, Cubatão, Guarujá, Itanhaém, Mongaguá, Peruíbe, Praia Grande, Santos e São Vicente.

Comunidades bentônicas têm sido amplamente utilizadas nos programas de monitoramento ambiental. A maioria dos organismos é séssil ou sedentária e podem indicar graus de poluição por alterar a composição da comunidade faunística. Além disso, incluem espécies com diferentes tolerâncias ao agente poluidor, como metais pesados, organoclorados, esgoto, entre outros. (Warwick, 1986; Bilyard, 1987; Ahn et al., 1995). A diversidade, abundância e dominância de espécies estão diretamente associadas às condições ambientais, tais como salinidade, temperatura, oxigênio dissolvido, variações de marés, ação de ondas, topografia, granulometria, entre outros (Snelgrove e Butman, 1994; McLachlan, 1996). A interação desses fatores é responsável pela estabilidade do sistema e alterações provocadas direta ou indiretamente pela ação do homem podendo desequilibrá-lo. Se as alterações forem frequentes, o desequilíbrio pode eliminar espécies sensíveis, substituindo-as por espécies oportunistas, provocando modificações nos níveis tróficos superiores da comunidade faunística (Bilyard, 1987).

Anelídeos poliquetas é o grupo dominante na região estudada e têm sido amplamente utilizados em programas de monitoramento ambiental, pois a diversidade e abundância relacionadas com os padrões de distribuição podem revelar se um determinado ambiente encontra-se ou não impactado (Pearson e Rosenberg, 1978; Choi e Koh, 1984; Pocklington e Wells, 1992; Rizzo e Amaral, 2000, 2001a, b). Dependendo dos fatores hidrodinâmicos e da heterogeneidade do substrato, os poliquetas podem dominar tanto em riqueza quanto em número de indivíduos, sendo representados por mais gêneros do que qualquer outro grupo animal (Brown e McLachlan, 1990; Amaral et al., 1995). Desempenham importante papel na cadeia trófica marinha, servindo como base alimentar para inúmeros organismos. Para algumas espécies de peixes e crustáceos, os poliquetas representam uma proporção superior a $80 \%$ do alimento ingerido (Amaral e Migotto, 1980). 


\section{MATERIAIS E MÉTODOS}

A Figura 2 ilustra a metodologia empregada no desenvolvimento deste estudo. A Modelagem Conceitual de Dados está intrinsicamente ligada às diversas Referências Bibliográficas existentes sobre o tema e as reais necessidades dos usuários do sistema, que em paralelo, subsidiam e refinam o modelo empregado. As referências utilizadas para este estudo foram: Codesp (2008, 2010), Embraport (2003), Tommasi (1979), Heitor (2002), Ferreira (2008).

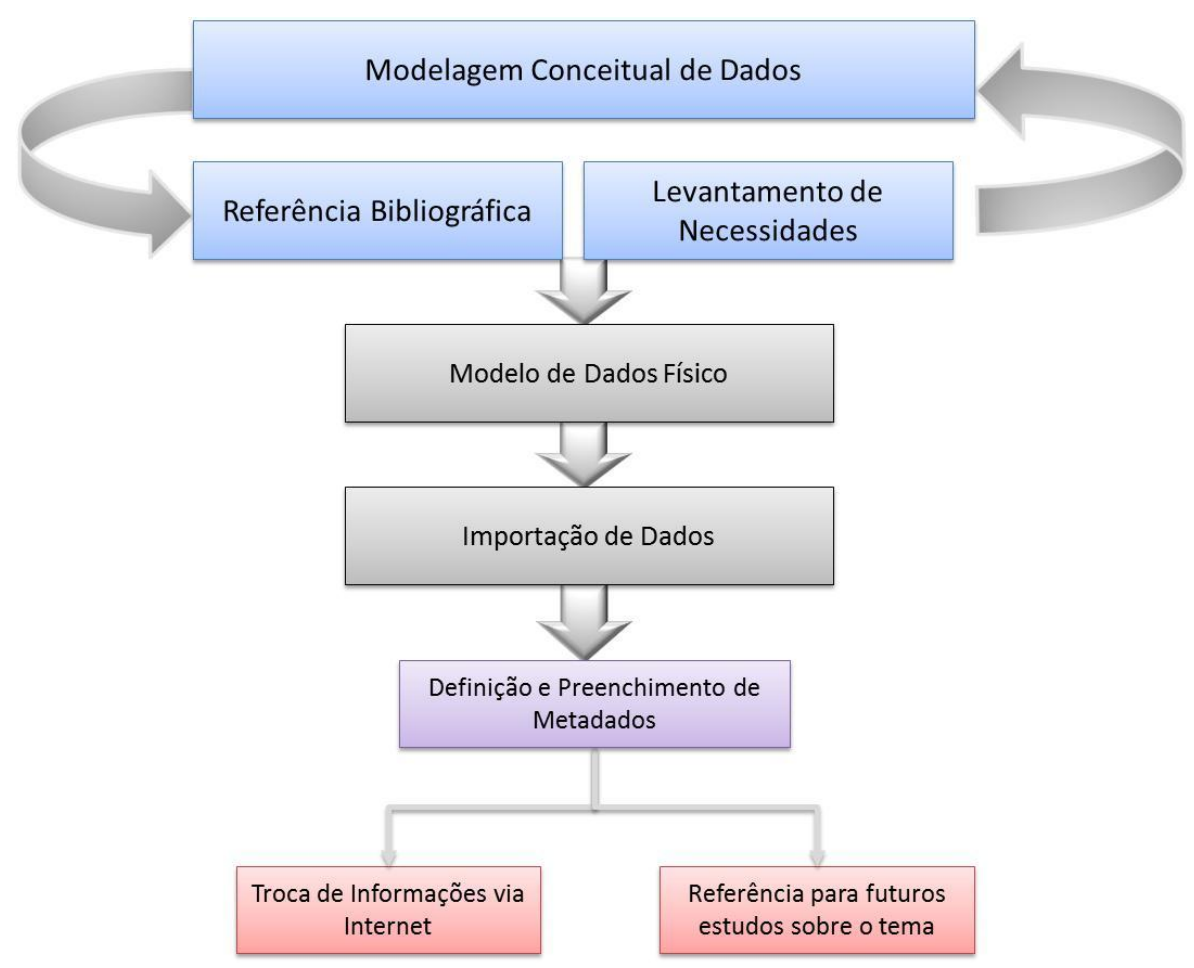

Figura 2. Resumo de metodologia aplicada.

Uma vez definido o Modelo Conceitual, adequado às fontes bibliográficas existentes, as necessidades dos usuários e ao tema em questão, os dados devem passar por um processo de Importação de Dados a um Modelo de Dados Físico que normalmente é representado em um Sistema Gerenciador de Banco de Dados tais como Oracle, Microsoft SQL Server, PostgreSQL, entre outros.

A Definição e o Preenchimento de Metadados são essenciais para que se possa documentar corretamente todos os passos realizados na definição das fontes e adequações nos dados, com o objetivo de facilitar a compreensão e o correto consumo destas informações em uma IDE. Os metadados ajudam a organizar e manter o investimento de uma organização, evitam duplicidade de esforços, além de facilitar e prover informações para consumo (GSDI, 2004).

Além disso, a correta parametrização de metadados também permite que tais dados, hoje armazenados em bibliotecas e documentos analógicos, possam ser consumidos por sistemas terceiros de maneira simples e direta por meio de Serviços Geoespaciais como WebMap Service (WMS), Web Feature Service (WFS), Catalog Service Web (CSW), segundo padrão definido pela Open Geospatial Consortium (OGC, 2011), que é exatamente o que representa a troca de informações via Internet e garante a interoperabilidade. 
Por fim, a expectativa é que o desenvolvimento de tal metodologia possa se tornar uma referência em futuros estudos sobre o tema ou similares, tanto em relação aos procedimentos realizados, quanto à agregação de levantamentos inéditos ao modelo existente, permitindo a troca de informações entre instituições, órgãos públicos, pesquisadores e a todos que destas informações necessitarem.

Especificamente neste artigo são discutidas as seguintes etapas da metodologia supracitada (Figura 2): Modelagem Conceitual de Dados, Referências Bibliográficas, Modelo de Dados Físico e Importação de Dados.

\section{Modelo de dados}

A evolução da tecnologia proporcionou acesso mais rápido e fácil aos dados espaciais, que permitiu apoiar a tomada de decisão por parte de gestores, uma vez que é possível inserir nas análises um conjunto de dados espaciais. Por outro lado, a produção de grande quantidade de dados pode também ser um problema, pois podem ter sido produzidos em diferentes padrões de software, escalas, propósitos, etc., e a falta de documentação (metadados), dificulta o consumo destas informações. Câmara e Lima Junior (2002) evidenciam suas preocupações com a busca por padrões no armazenamento e troca de informações espaciais entre os produtores: "Um dos desafios mais importantes no uso das geotecnologias é o intercâmbio de dados espaciais, impulsionado principalmente pelo alto custo de produção deste tipo de dado. A falta de modelos conceituais comuns acarreta problemas na troca de dados entre organizações utilizando Sistema de Informação Geográfica (SIGs) distintos, que incluem distorção de dados, comprometimento de qualidade da informação, perda de definições de atributos e georreferenciamento".

A busca pela interoperabilidade entre diferentes dados geoespaciais parte da adoção de um Modelo de Dados para a organização conceitual de dados e sua posterior disponibilização para diferentes organizações que utilizam padrões pré-definidos como Serviços Geoespaciais (Web Services), seguindo o padrão OGC. No Brasil, a crescente preocupação por padronização/ acessibilidade de dados geoespaciais fez com que fosse criada a Infraestrutura Nacional de Dados Espaciais (INDE-BR), sob tutela da Comissão Nacional de Cartografia (CONCAR). Dentre as atividades já realizadas, pode-se destacar a Especificação Técnica para a Aquisição de Dados Geoespaciais Vetoriais (ET-EDGV) que: "tem por objetivo padronizar e orientar todo o processo de aquisição da geometria dos vários tipos de dados geoespaciais vetoriais, presentes na Especificação Técnica para Estruturação de Dados Geoespaciais Vetoriais (ET-EDGV), da CONCAR, para qualquer que seja o insumo a ser utilizado (levantamento de campo, fotografias aéreas, imagens de sensores orbitais, etc.), visto que os processos de aquisição são similares." (Lunardi et al., 2009).

Diante deste cenário, torna-se cada vez mais necessário que haja uma padronização no levantamento, organização e documentação de dados espaciais, para que este possa ser utilizado por terceiros. Um modelo de dados, seja este com características geográficas ou não, é referente ao processo de abstração na qual apenas os elementos essenciais da realidade para um determinado estudo são considerados (Lisboa Filho e Iochpe, 1999).

O processo de abstração é parte fundamental na criação de sistemas de informações. Trata-se, portanto, da transposição de entidades do mundo real e suas interações para um banco de dados informatizado que realiza a descrição dos possíveis conteúdos dos dados, além de estruturas e regras das entidades escolhidas. Quando se considera o âmbito espacial, esta abstração ainda possui algumas especificidades referentes à localização espacial, o tempo de observação, a precisão de obtenção e representação das informações geográficas.

Para o processo de abstração específico para este artigo foi utilizado o modelo Object Modeling Technique for Geographic Applications (OMT-G), que é derivado do OMT convencional, baseado no método conceitual Orientado a Objeto (OO) e Diagrama de Classes 
UML (Unified Modeling Language), conforme destaca Borges et al. (2001) e: "provê primitivas para modelar a geometria e a topologia dos dados geográficos, oferecendo suporte a estruturas topológicas "todo-parte", estruturas de rede, múltiplas representações de objetos e relacionamentos espaciais. Além disso, o modelo permite a especificação de atributos alfanuméricos e métodos associados para cada classe. Os principais pontos do modelo são sua expressividade gráfica e sua capacidade de codificação, uma vez que anotações textuais são substituídas pelo desenho de relacionamentos explícitos, que denotam a dinâmica da interação entre os diversos objetos espaciais e não espaciais." (Câmara et al., 2005).

Além disso, trata-se do mesmo padrão adotado pela INDE, constituída em 2008 pelo Decreto $\mathrm{N}^{\circ}$ 6.666, de 27 de Novembro de 2008, que possui a missão de promover o adequado ordenamento na geração, armazenamento, acesso, compartilhamento, disseminação e uso dos dados geoespaciais (Lunardi et al., 2009). Para maiores detalhes sobre este e outros modelos analisar as seguintes bibliografias: Lisboa Filho e Iochpe (1999), Borges et al. (2001) e Câmara et al. (2005).

Uma vez realizado o levantamento das fontes de dados e a definição da metodologia a ser empregada, iniciou-se a construção do modelo de dados. Em se tratando especificamente do tema Macrobentos, percebe-se que há uma real dificuldade em, primeiramente, encontrar estudos semelhantes ao redor do mundo e em segundo, estarem vinculados e preocupados com a questão espacial. Assim, parte dos estudos existentes não possuem informações completas de levantamentos de amostras realizadas em campo (sistema de coordenadas, forma de armazenamento, processos e metodologia realizada) e, portanto, acabam por dificultar a agregação e consequentemente a modelagem conceitual dos estudos. Como já destacado por (Rajabifard et al., 2008), normalmente os levantamentos são feitos para um propósito específico e raramente são compartilhados com outras organizações.

\section{RESULTADOS E DISCUSSÃO}

O intuito da modelagem é exatamente para levantar os fenômenos intrínsecos ao tema em questão, entendê-los e organizá-los de maneira lógica com o objetivo de poder utilizá-los em futuros portais, atlas, entre outros. Para a construção do modelo foi utilizado o software Microsoft Visio 2010, com uma extensão específica aderente ao modelo OMT-G. Cada classe representada por um pictograma que contem as informações referentes ao tipo de representação espacial (linha, ponto, polígono, etc.) ou não espacial, atributos e operações seguindo o modelo OMT-G, como mostra a Figura 3.

\begin{tabular}{|c|c|c|c|c|c|c|c|c|}
\hline LINHA & PONTO & POLÍGONO & \multicolumn{2}{|c|}{$\begin{array}{c}\text { LINHA } \\
\text { UNI-DIRECIONADA }\end{array}$} & \multicolumn{2}{|c|}{$\begin{array}{c}\text { LINHA } \\
\text { BI-DIRECIONADA }\end{array}$} & \multicolumn{2}{|r|}{ Nó } \\
\hline \begin{tabular}{|l|l|}
- & $\begin{array}{l}\text { Nome } \\
\text { da classe }\end{array}$ \\
\end{tabular} & \begin{tabular}{|l|l|} 
is & $\begin{array}{l}\text { Nome } \\
\text { da Classe }\end{array}$ \\
\end{tabular} & \begin{tabular}{l|l}
$\square$ & $\begin{array}{l}\text { Nome } \\
\text { da classe }\end{array}$ \\
\end{tabular} & $\rightarrow$ & $\begin{array}{l}\text { Nome } \\
\text { da Classe }\end{array}$ & $\leftrightarrow$ & $\begin{array}{l}\text { Nome } \\
\text { da Classe }\end{array}$ & 0 & $\begin{array}{l}\text { Nome } \\
\text { da Classe }\end{array}$ \\
\hline Atributos Grancos & Atributos Granticos & Atributos Grancos & \multicolumn{2}{|c|}{ Atributos Graficos } & \multicolumn{2}{|c|}{ Atributos Grancos } & \multicolumn{2}{|c|}{ Atributos Grancos } \\
\hline Atributos & Atributos & Atrioutos & & Atributos & & Atributos & & Atributos \\
\hline Operaçбes & Operaçбes & Operaçbles & & peraçбes & & Dperaçbes & & Operaçbles \\
\hline Ex: Muro & Ex: Árvore & Ex: Lote & Ex: & $\begin{array}{l}\text { recho rede } \\
\text { esgoto }\end{array}$ & Ex: & $\begin{array}{l}\text { Trecho rede } \\
\text { de água }\end{array}$ & Ex:P & oço de Visita \\
\hline
\end{tabular}

Figura 3. Exemplo de representação de classes.

Fonte: Adaptado de Borges et al. (2001). 
CARVAlHO, G. N.; GIANNOTTI, M. A.; SARTOR, S.; QUINTANILHA, J. A. Modelagem para integração de dados sobre macrobentos em Infraestrutura de Dados Espaciais. Ambi-Agua, Taubaté, v. 7, n. 2, p. 195-213, 2012. (http://dx.doi.org/10.4136/ambi-agua.774)

A Figura 4 apresenta o modelo desenvolvido para Macrobentos utilizando a metodologia proposta.

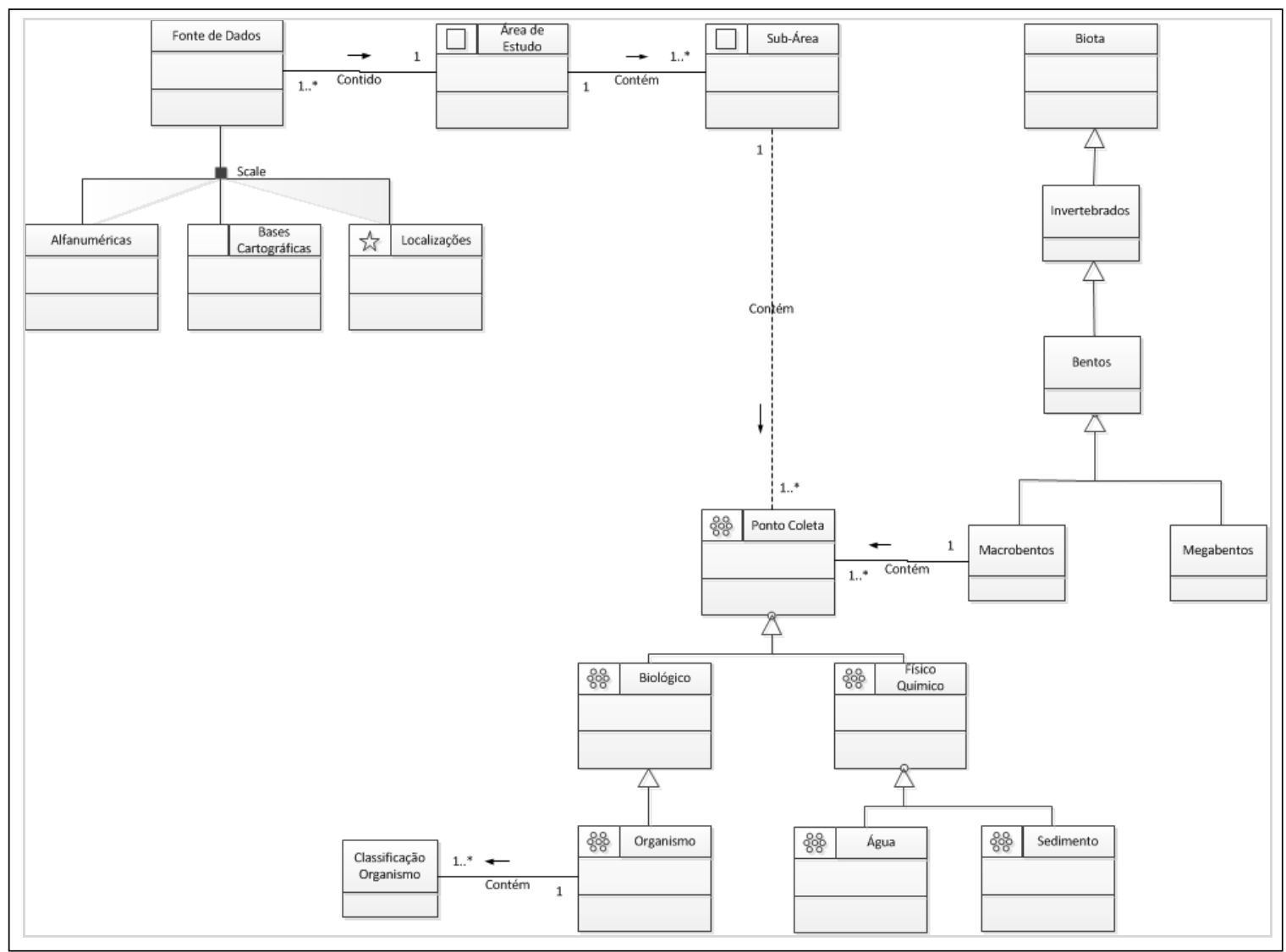

Figura 4. Modelagem de Dados Espaciais Teórico para o tema macrobentos.

A Tabela 1 ilustra com mais detalhes a composição do Modelo de Dados Espaciais Teórico seguindo o padrão OMT-G. Em cada etapa do processo é possível observar os diversos tipos de simbologia que compõem as classes, cada uma com seu significado intrínseco.

Tabela 1. Detalhamento do modelo teórico (abstrato) segundo OMT-G.

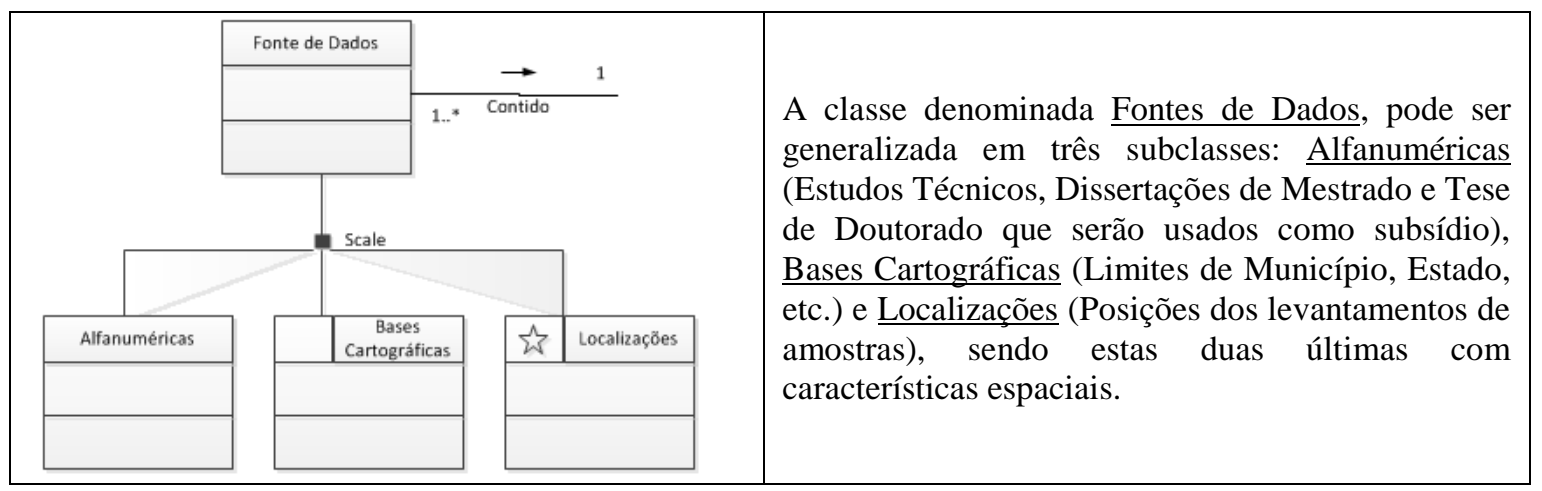


CARVAlHO, G. N.; GIANNOTTI, M. A.; SARTOR, S.; QUINTANILHA, J. A. Modelagem para integração de dados sobre macrobentos em Infraestrutura de Dados Espaciais. Ambi-Agua, Taubaté, v. 7, n. 2, p. 195-213, 2012. (http://dx.doi.org/10.4136/ambi-agua.774)

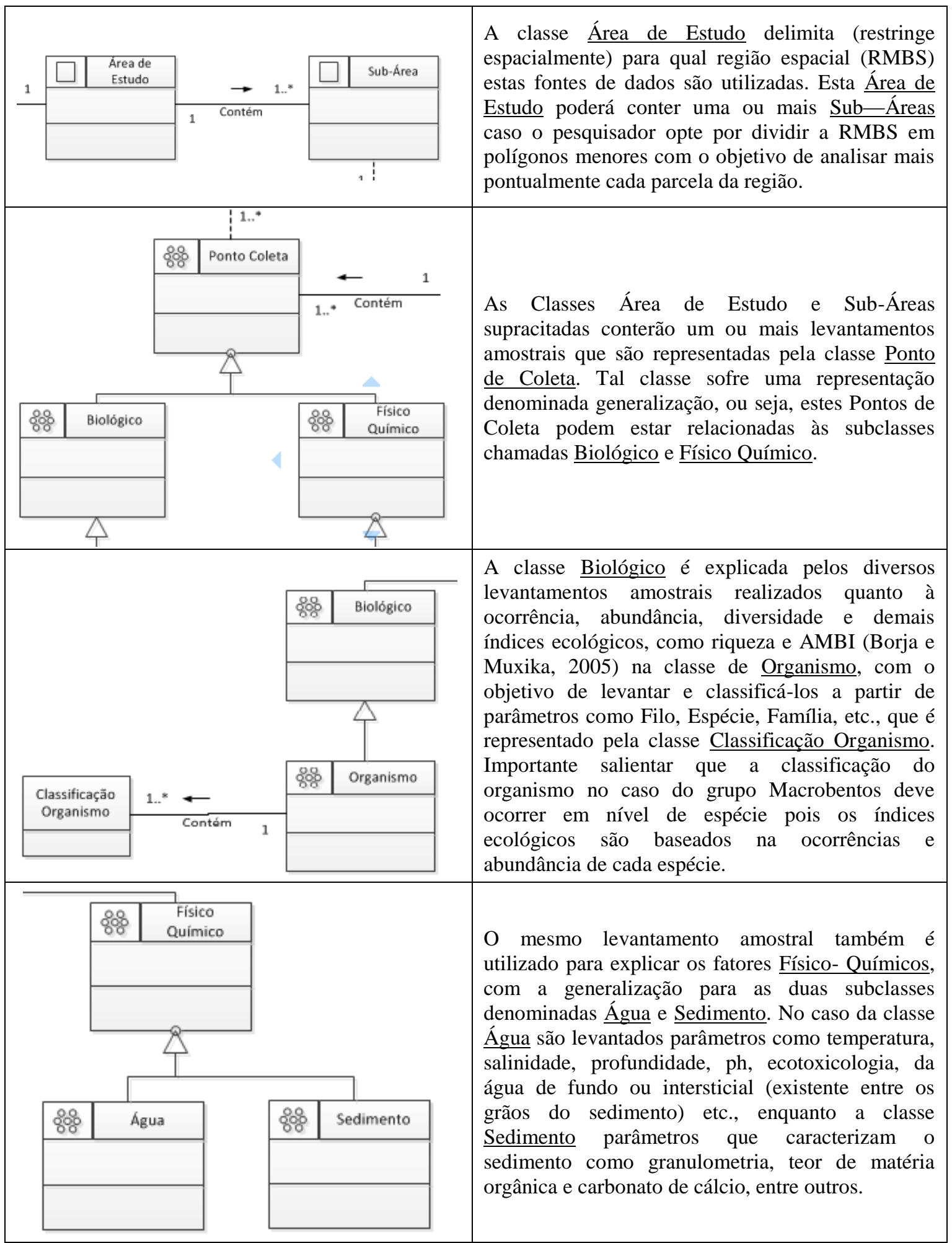




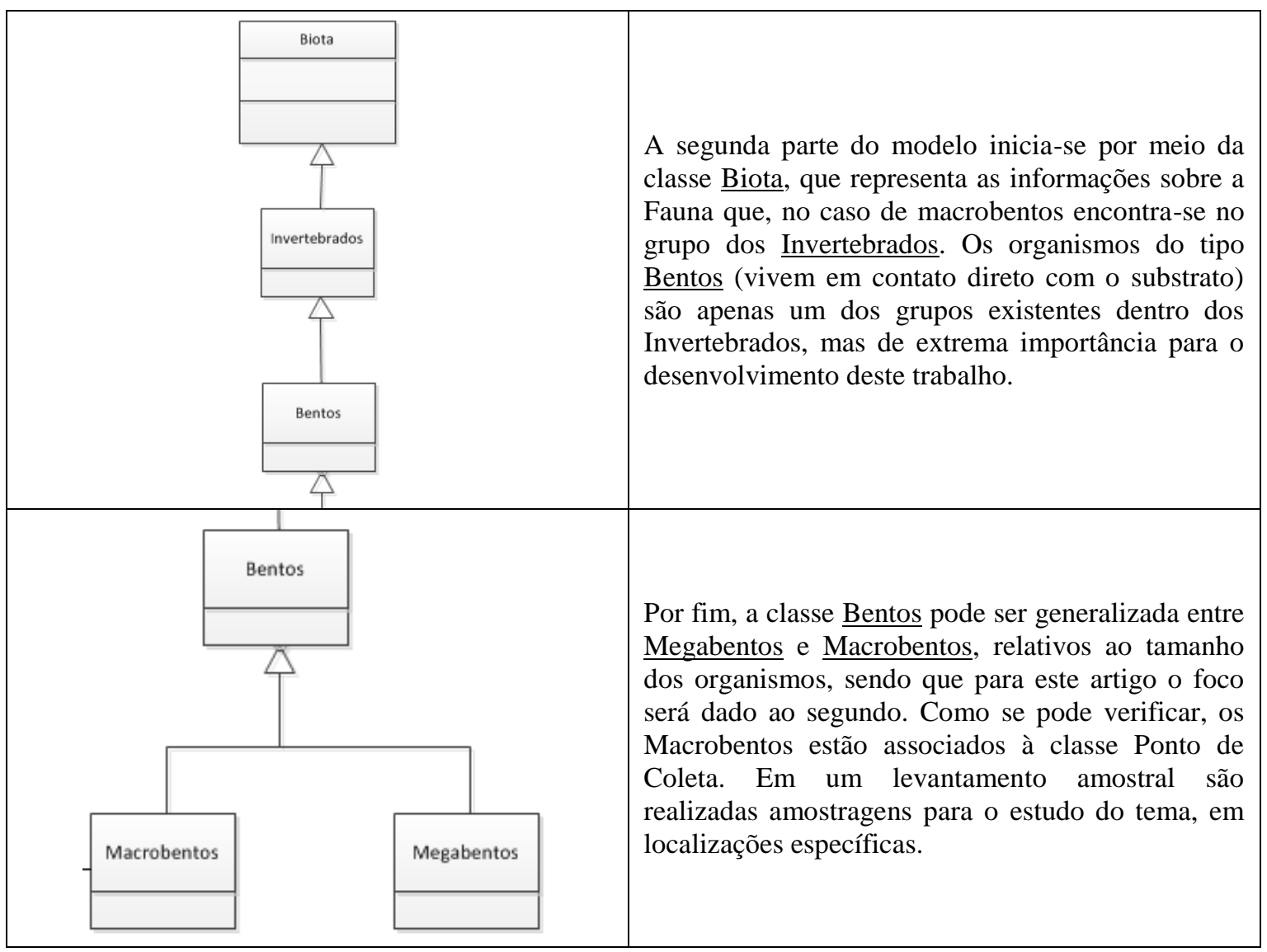

Com o modelo abstrato do banco de dados definido, este poderá servir como referência para a construção do modelo de implementação física e a posterior inserção das informações provenientes dos estudos supracitados. As classes bem definidas auxiliam o desenvolvedor a organizar e estruturar melhor a organização das tabelas e suas relações, tanto espaciais como alfanuméricas.

O modelo de implementação física apresentado na Figura 5, exemplifica a utilização do modelo abstrato do banco de dados baseado nas necessidades do projeto Atlas, como por exemplo determinar a quantidade de organismos existentes em uma área específica. Vale salientar que tal modelo pode também ser adaptado conforme existirem novas demandas.

Nesta primeira parte, representado pela (Figura 5), é explicitada apenas a relação entre a Área de Estudo e suas possíveis subáreas. Para a delimitação das áreas (zonas ecológicas) deverá ser levado em consideração os índices ecológicos indicados pelos Macrobentos. Os demais parâmetros como a contribuição dos recursos hídricos, da salinidade e hidrodinamismo (especialmente regime de marés), subsidiam o entendimento sobre as áreas impactadas ou conservadas.

A segunda parte do modelo de dados (Figura 6) transcreve a classe Biota na visão do tema Macrobentos. Uma característica específica para este tema condiz com o fato de que os estudos realizados nem sempre possuem as mesmas informações levantadas ou padronizadas. O pesquisador realiza o levantamento que utiliza um valor de medida de volume que não está padronizado e pode implicar em diferenças nos dados obtidos; isto novamente, porque cada estudo é realizado com enfoques diferentes e sem a preocupação no compartilhamento de dados. 


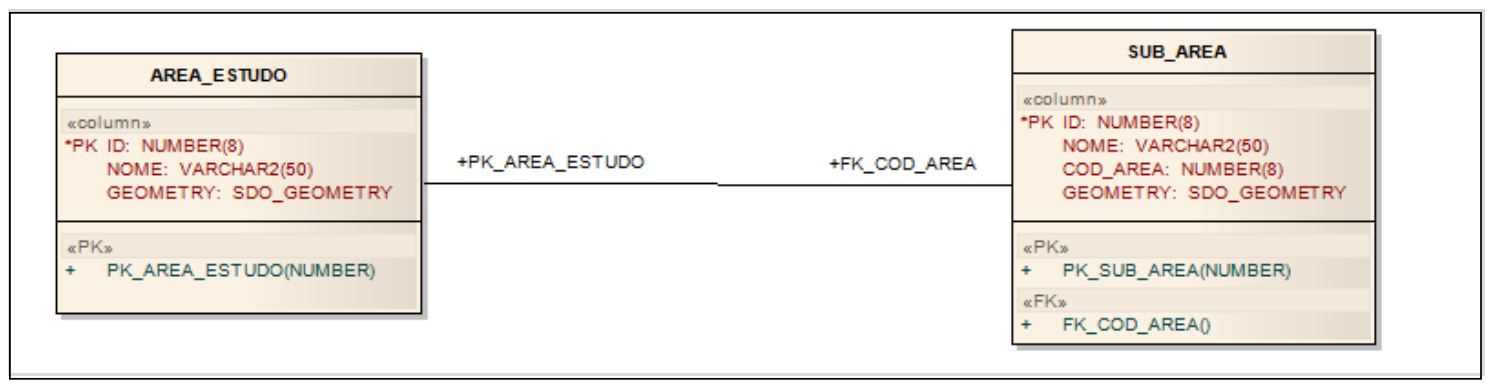

Figura 5. Parte 1 do Modelo físico de dados.

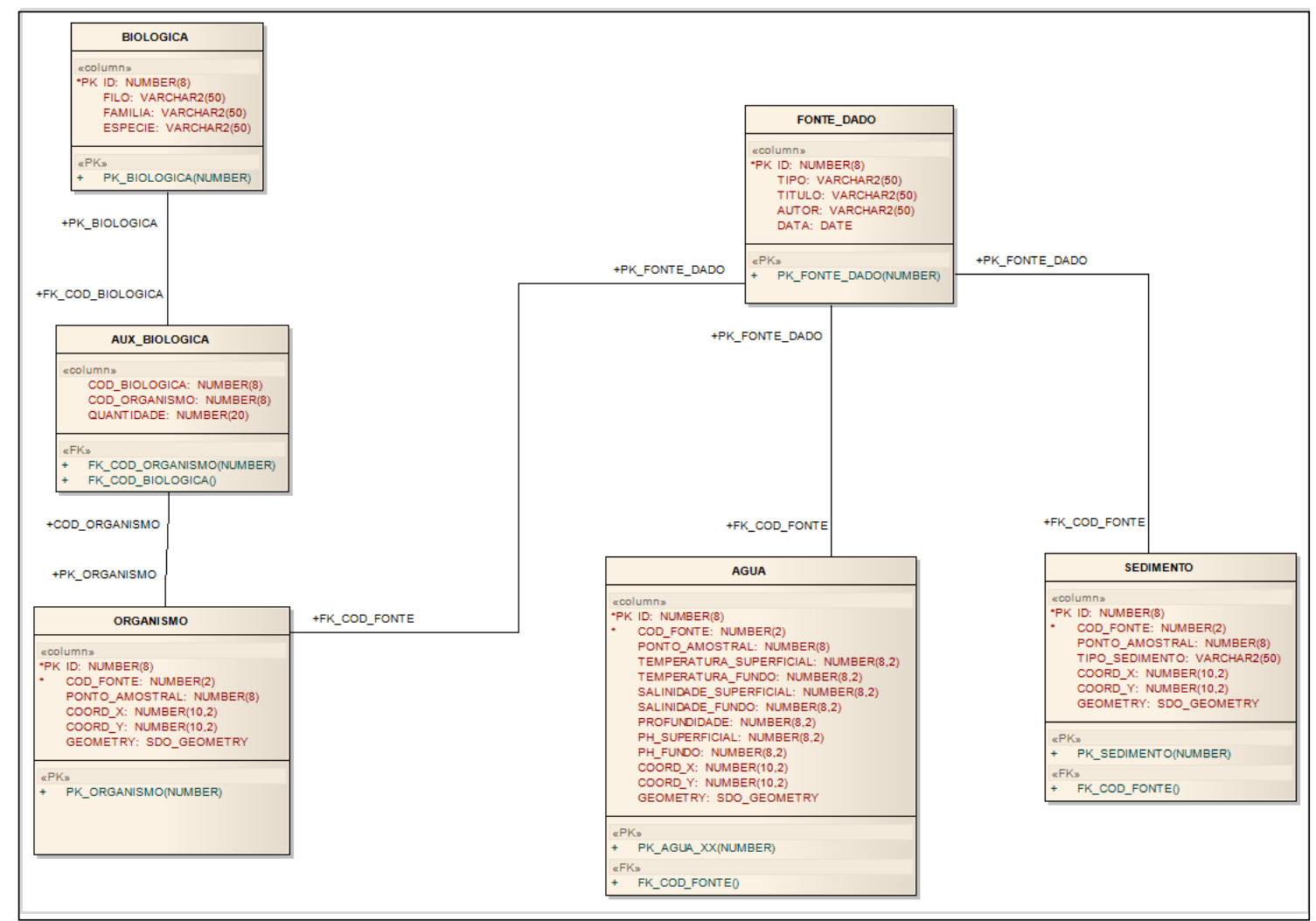

Figura 6. Parte 2 do modelo físico de dados.

\section{CONCLUSÃO}

Neste trabalho foi proposto um modelo conceitual sobre Macrobentos, idealizado para ser utilizado numa IDE. Além do modelo em si, foram indicadas as etapas necessárias para a sistematização e modelagem de dados ambientais, a exemplo do objeto estudado. Constatouse que a modelagem de dados ambientais, além de ser uma alternativa para a representação do conhecimento de uma forma estruturada, exerce um papel facilitador na integração de dados provenientes de diversas fontes, para que possam ser compartilhados de maneira padronizada em Atlas Web. A sequência metodológica da construção de um modelo de dados espaciais é descrita, levando em consideração a integração de conhecimento de especialistas sobre os temas abordados.

Especificamente para a área ambiental e o tema Macrobentos, quando da aquisição e coleta dos dados, foi possível concluir que grande parte dos dados existentes para a Região Metropolitana da Baixada Santista não se encontram na forma computacional. Estão dispersos em vários documentos, depositados em diferentes instituições. Não há a preocupação com a 
questão espacial e com a padronização no processo de constituição da informação, dificultando o acesso aos dados por parte dos pesquisadores, dos tomadores de decisão, entre outros. Essa realidade é a mesma encontrada para as demais regiões do Brasil, o que implica em constante retrabalho quando há a necessidade de estudar uma região.

Somado a isso, notou-se também que, quando se trabalha com dados ambientais coletados em pesquisas de campo, diferentes metodologias de coleta são utilizadas. Este fato dificulta ainda mais a integração dos dados, que podem apresentar incompatibilidade metodológica inviabilizando sua comparação ou integração. Verificou-se que um modelo conceitual para integração de dados, serve também como um sinalizador da importância dessas questões metodológicas de coleta, e da necessidade em se registrar certas informações, sem as quais o processo de integração pode ser inviabilizado. Dados provenientes de amostras coletadas em determinado estudo podem ser incompatíveis com outros dados coletados para a mesma área por diferenças metodológicas. Essa constatação alerta não apenas para as questões de padronização, como também, para a importância o levantamento dos metadados (dados sobre os dados) ou a sua criação para os dados já existentes.

$\mathrm{O}$ artigo mostra que, apesar das condições supracitadas, é possível conceber-se um modelo de dados que abrange um largo espectro de diferentes fontes de informação e que o uso das técnicas OMT-G e de outros procedimentos computacionais tidos como padrões em modelagem de dados, podem ajudar na elaboração de produtos mais úteis aos tomadores de decisão e aos demais usuários de dados ambientais.

O trabalho tem também o propósito de fomentar a discussão sobre a necessidade de padronização no levantamento, organização e disponibilização de dados, sejam estes vinculado à área ambiental, social ou econômica, para uso em portais baseados em IDEs. Tal discussão deve ser aprofundada em futuros estudos, especialmente neste momento, quando estão sendo cada vez mais discutidas a disponibilização e integração de dados por meio de serviços, metodologia de levantamentos, etc., como salienta a própria Infraestrutura Nacional de Dados Espaciais (CONCAR, 2011).

A construção de um modelo de dados espacial, como o apresentado neste estudo poderá ser utilizado como referência para novas pesquisas com objetivos semelhantes.

\section{AGRADECIMENTOS}

Os autores agradecem à Fundação de Amparo à Pesquisa do Estado de São Paulo (FAPESP 06/51780-2) pelo apoio financeiro na realização desta pesquisa, ao Conselho Nacional de Desenvolvimento Científico e Tecnológico $(\mathrm{CNPq})$ pelo apoio aos pesquisadores bolsistas, à Companhia Docas do Estado de São Paulo (CODESP) pelo fornecimento de dados, à empresa Imagem Sensoriamento Remoto S/C Ltda pelo fornecimento de softwares e a Escola Politécnica da Universidade de São Paulo (EPUSP), em particular ao Laboratório de Geoprocessamento, pela disponibilização da infraestrutura e apoio logístico.

\section{REFERÊNCIAS}

AHN, I. Y.; KANG, Y. C.; CHOI, J. The influence of industrial effluents on intertidal benthic communities in Panweol, Kyeonggi Bay (Yellow Sea) on the west coast of Korea. Marine Pollution Bulletin, v. 30, n. 3, p. 200-206, 1995. http://dx.doi.org/10.1016 /0025-326X(94)00125-S.

AMARAL, A. C. Z.; MIGOTTO, A. E. Importância dos anelídeos poliquetas na alimentação da macrofauna demersal e epibentônica da região de Ubatuba. Brazilian Journal of oceanography, São Paulo, v. 29, n. 2, p. 31-35, 1980. 
AMARAL, A. C. Z.; MORGADO, E. H.; PARDO, E. V.; REIS, M. O. Estrutura da comunidade de poliquetos da zona entre marés em praias da Ilha de São Sebastião (SP). Publicação Especial do Instituto de Oceanografia, São Paulo, v. 11, p. 229-237, 1995.

ARAUJO, S. I.; SILVA, G. H.; MUEHE, D. Mapas de sensibilidade ambiental a derrames de óleo: ambientes costeiros, estuarinos e fluviais. 2. ed. Rio de Janeiro: CENPES/Petrobras, 2007. $134 \mathrm{p}$.

AUSTRALIAN MARINE SPATIAL INFORMATION SYSTEM - AMSIS. 2011. Disponível em: <http://www.ga.gov.au/imf-amsis2>. Acesso em: 07 set. 2011.

AUSTRALIAN OCEAN DATA CENTRE JOINT FACILITY - AODCJF. 2011. Disponível em: <http://www.aodc.gov.au/index.php?id=19>. Acesso em: 07 set. 2011.

BARTLETT, D.; SMITH, J. GIS for coastal management. Boca Raton: CRC Press, 2005. $315 \mathrm{p}$.

BILYARD, G. R. The value of benthic infauna in marine pollution monitoring studies. Marine Pollution Bulletin, v. 18, n. 11, p. 581-585, 1987.

BORGES, K. A. V.; DAVIS, C. A.; LAENDER, A. H. F. OMT-G: an object-oriented data model for geographic applications. Geoinformatica, v. 5, n. 3, p. 221-260, 2001. http://dx.doi.org/10.1023/A:1011482030093

BORJA, A. MUXIKA, I. Guidelines for the use of AMBI (AZTI's marine biotic index) in the assessment of the benthic ecological quality. Marine Pollution Bulletin, v. 50, n. 7, p. 787-789, 2005. http://dx.doi.org/10.1016/j.marpolbul.2005.04.040.

BROWN, A. C.; MCLACHLAN, A. Ecology of sandy shores. Amsterdam: Elsevier, 1990. $327 \mathrm{p}$.

CÂMARA, G.; LIMA JR., P. O. GeoBR: intercâmbio sintático e semântico de dados espaciais. Informática Pública, Belo Horizonte, v. 4, n. 2, p. 251-281, 2002.

CÂMARA, G.; DAVIS, C. A.; VINHAS, L.; QUEIROZ, G. R.; CASANOVA, M. Bancos de dados geográficos. Curitiba: MundoGeo, 2005.

CANADIAN GEOSPATIAL DATA INFRASTRUCTURE - CGDI. Geoconnections. 2011. Disponível em: <http://www.geoconnections.org/en/index.html>. Acesso em: 23 mar. 2011.

CHAN, T. O.; FEENEY, M.; RAJABIFARD, A.; WILLIAMSON, I. The dynamic nature of spatial data infrastructures: a method of descriptive classification. Geomatica, v. 55 , n. 1, p. 451-462, 2001.

CHOI, J. W.; KOH, C. H. A study on the polychaete community in Kwangyang Bay, southern coast of Korea. J. Ocean. Soc. Korea, v. 15, n. 2, p. 153-162, 1984.

COMPANHIA DOCAS DO ESTADO DE SÃO PAULO - CODESP. Relatório técnico do estudo de impacto ambiental do aprofundamento do canal e bacias de evolução do Porto Organizado de Santos. [S.1.]: Fundação Ricardo Franco, 2008. 
COMPANHIA DOCAS DO ESTADO DE SÃO PAULO - CODESP. Relatório sobre monitoramento das atividades de dragagem na área de disposição oceânica do material dragado pela CODESP e suas regiões adjacentes (Município de Santos/SP): 2005 até 2010. [S.1.: s.n.], 2010.

COMPANHIA DE TECNOLOGIA DE SANEAMENTO BÁSICO - CETESB. Sistema estuarino de Santos e São Vicente. São Paulo, 2001.

COMPANHIA DE TECNOLOGIA DE SANEAMENTO BÁSICO - CETESB. Relatório de qualidade das águas interiores do Estado de São Paulo: balneabilidade das praias. São Paulo, 2004.

COMPANHIA DE TECNOLOGIA DE SANEAMENTO BÁSICO - CETESB. Relatório de qualidade das águas litorâneas do estado de São Paulo: balneabilidade das praias. São Paulo, 2007.

COMPANHIA DE TECNOLOGIA DE SANEAMENTO BÁSICO - CETESB. Relatório de qualidade das águas litorâneas do estado de São Paulo. São Paulo, 2008.

COMPANHIA DE TECNOLOGIA DE SANEAMENTO BÁSICO - CETESB. Relatório de qualidade das águas litorâneas do estado de São Paulo. São Paulo: CETESB, 2009.

COMISSÃO NACIONAL DE CARTOGRAFIA - CONCAR. Plano de ação para implantação da infraestrutura cacional de dados espaciais. 2011. Disponível em: <www.concar.ibge.gov.br>. Acesso em: 23 mar. 2011.

CROMPVOETS, J.; BREGT, A.; RAJABIFARD, A.; WILLIAMSON, I. Assessing the worldwide developments of national spatial data clearinghouses. International Journal of Geographical Information Science, v. 18, n. 7, p. 665-689, 2004. http://dx.doi.org/ 10.1080/13658810410001702030.

DAVIS JR. C. A.; ALVES, L. L. Local spatial data infrastructures based on a service oriented architecture. In: BRAZILIAN SYMPOSIUM ON GEOINFORMATICS, 7., 20-23 nov. 2005, Campos do Jordão. Proceedings... São José dos Campos: INPE, 2005. p. 30-45.

EMPRESA BRASILEIRA DE TERMINAIS PORTUARIOS - EMBRAPORT. EIA-RIMA sobre a construção do terminal portuário da Embraport. Santos, 2003. Vol. III.

GEHARDI, D. F. M.; CABRAL, A. P.; KLEIN, A. H. F.; MUEHE, D. C. E. H.; NOERBERG, M. A.; TESSLER, M. G. et al. Mapping the sensitivy to oil spill of the Santos basin coastline, Southeast Brazil. Brazilian Journal of Aquatic Science and Technology, Santos, v. 12, n. 2, p. 11-31, 2008. Disponível em: <https://www6.univali.br/seer/index.php/bjast/article/viewFile/659/533>. Acesso em: 20 ag. 2011.

FERREIRA, J. A. Estudos das associações de anelídeos Polychaeta da Baía de Santos e plataforma Continental Adjacente (SP, Brasil) e suas interrelações com parâmetros físicos e geoquímicos estruturadores. 2008. 204f. Tese (Doutorado em Oceanografia Básica) - Instituto Oceanográfico, Universidade de São Paulo, São Paulo, 2008 .

GLOBAL SPATIAL DATA INFRASTRUCTURE ASSOCIATION - GSDI. The SDI Cookbook. Version 2.0, 2004. Disponível em: <http://www.gsdi.org/ gsdicookbookindex>. Acesso em: 20 jan. 2011. 
HEITOR, S. R. Composição e distribuição da macrofauna bentônica em áreas sob a influência da disposição oceânica de esgotos municipais da Baixada Santista e no Canal de São Sebastião. 2002. 245f. Tese (Doutorado em Oceanografia Básica) Instituto Oceanográfico, Universidade de São Paulo, São Paulo, 2002.

HJELMAGER, J.; MOELlERING, H.; COPPER, A.; DELGADO, T.; RAJABIFARD, A.; RAPANT, P. et al. An initial formal model for spatial data infrastructures. International Journal of Geographic Information Science, v. 22, p. 1295-1309, 2008 .

INTERNATIONAL COASTAL ATLAS NETWORK - ICAN. 2011. Disponível em: <http://ican.science.oregonstate.edu/home>. Acesso em: 18 ago. 2011.

KENNISH, M. J. Practical handbook of estuarine and marine pollution. Boca Raton: CRC Press, 1997. 524 p.

LISBOA FILHO, J.; IOCHPE, C. Um estudo sobre modelos conceituais de dados para projeto de bancos de dados geográficos. Informática Pública, Belo Horizonte, v. 2, p. 67-90, 1999.

LUNARDI, O. A.; ISSMAEL, L. S.; ALVES, P. D. V.; CARVALHO, L. H. M. Aquisição da geometria de dados geoespaciais para a infra-estrutura nacional de dados espaciais (INDE). In: SIMPÓSIO BRASILEIRO DE SENSORIAMENTO REMOTO, 14., 25-30 abril 2009, Natal. Anais... Belo Horizonte: SBSR, 2009. p. 1795-1802.

MARINE ENVIRONMENTAL DATA \& INFORMATION NETWORK - MEDIN. Marine geoportal. 2011. Disponível em: <http://www.oceannet.org>. Acesso em: 02 set. 2011.

MARINE IRISH DIGITAL ATLAS. Digital Atlas. 2011. Disponível em: <http://mida.ucc.ie/pages/about.htm>. Acesso em 15 de outubro de 2011.

MASSER, I.; RAJABIFARD, A.; WILLIAMSON, I. Spatially enabling governments through SDI implementation. International Journal of Geographical Information Science, v. 22, n. 1, p. 5-20, 2008.

MCLACHLAN, A. Physical factors in benthic ecology: effects of changing sand size on beach fauna. Marine Ecology Progress Series, v. 131, p. 205-217, 1996.

NATIONAL OCEANIC AND ATMOSPHERIC ADMINISTRATION - NOAA. Digital Coast. 2011. Disponível em: <http://www.csc.noaa.gov/digitalcoast/data>. Acesso em 10 de outubro de 2011.

NYBAKKEN, J. W. Marine biology: an ecological approach. 5. ed. São Francisco: Benjamin Cummings, 1995. $516 \mathrm{p}$.

OCEAN DATA AND INFORMATION NETWORK FOR AFRICA - ODINAFRICA. African marine atlas. 2011. Disponível em: 〈http://193.191.134.9/odinafrica3/data.html>. Acesso em: 12 jul. 2011.

OPEN GEOSPATIAL CONSORTIUM - OGC. Reference model. 2011. Disponível em: <http://www.opengeospatial.org/standards/orm>. Acesso em: 04 fev. 2011.

PEARSON, T. H.; ROSENBERG, R. Macrobenthic succession in relation to organic enrichment and pollution of the marine environment. Oceanography and Marine Biology: an Annual Review, v. 16, p. 229-311, 1978. 
POCKLINGTON, P.; WELLS, P. G. Polychaetes: key taxa for marine environmental quality monitoring. Marine Pollution Bulletin, v. 24, n.12, p. 593-598, 1992.

RAJABIFARD, A.; VAEZ, S. S.; WILLIAMSON, I. P. Building Seamless SDI to Facilitate Land and Marine Environments. In: INTERNATIONAL CONFERENCE FOR SPATIAL DATA INFRASTRUCTURE, 10., 25-29 feb. 2008, St. Augustine. Proceedings... St. Augustine: GSDI, 2008.

RAJABIFARD, A.; BINNS, A.; MASSER, I.; WILLIANSON, I. The role of the sub-national government and the private sector in future spatial data infrastructure. International Journal of Geographical Information Science, v. 20, n. 7, p. 727-741, 2006. http://dx.doi.org/10.1080/13658810500432224.

RIZZO, A. E.; AMARAL, A. C. Z. Temporal variation of annelids in the intertidal zone of beaches of the São Sebastião Channel, southern Brazil. Journal of the Marine Biological Association of the United Kingdom, v. 80, n. 6, p. 1007-1017, 2000.

RIZZO, A. E.; AMARAL, A. C. Z. Spatial distribution of annelids in the intertidal zone in São Sebastião Channel, Brazil. Scientia Marina, v. 65, n. 4, p. 323-331, 2001 a.

RIZZO, A. E.; AMARAL, A. C. Z. Environmental variables and intertidal beach annelids of São Sebastião Channel (State of São Paulo, Brazil). Revista de Biologia Tropical, Costa Rica, v. 49, n. 3, p. 849-857, 2001 b.

RIVERO, M. S.; ELÍAS, R.; VALLARINO, E. A. First survey of macrofauna in the Mar del Plata Harbor (Argentina), and the use of polychaetes as pollution indicators. Revista de Biolígia Marina y Oceanografía, Valparaiso, v. 40, n. 2, p. 101-108, 2005.

RODRÍGUEZ, J. J.; WINDEVOXHEL, N. J. Análisis regional de la situación de la zona marina costera centroamericana. Washington, D.C.: BID, 1998. Env. 121. Disponível em: <http://www.infoiarna.org.gt/media/file/areas/marino/documentos/interna/(3)\%20 An\%C3\%A1lisis\%20de\%20la\%20situaci\%C3\%B3n\%20marina\%20costera.pdf $>$. Acesso em: 25 jun. 2012.

SARTOR, S. M.; DEGASPARI, F. A. A balneabilidade das praias de Santos: discussão dos critérios oficiais de avaliação. In: CONGRESSO INTERAMERICANO DE ENGENHARIA SANITÁRIA E AMBIENTAL, 27., 3-8 dez. 2000, Porto alegre. Anais... Porto Alegre: ABES, 2000.

SARTOR, S. M.; HANS, M. F. P.; PALMER, L.; SARTOR, L. M.; LEAO, A. L. Coastal marine mapping as an ecosystem based management: the case study of the Baixada Santista Region - São Paulo, Brazil. Journal of Coastal Research, Gold Coast, v. 50, p. 1178-1182, 2007.

SARTOR, S. M.; PALM, A. S.; PALM, L.; SHINOHARA, E. J.; QUINTANILHA, J. A. Tools for coastal marine ecosystem-based management and geographically referred data integration: the Santos Region case study. In: GLOBAL SPATIAL DATA INFRASCTUCTURE WORLD CONFERENCE, jun. 2009, Rotterdam. Proceedings... Rotterdam: GSDI Association, 2009.

SMALL, C.; COHEN, J. E. Continental physiography, climate, and the global distribution of human population. Current Anthropology, Palisales, v. 45, n. 2, 2004. Disponível em: <http://lab.rockefeller.edu/cohenje/PDFs/312SmallCohenCA2004ALLFIGURES.pdf>. Acesso em: 12 jun. 2011. 
SNELGROVE, P. V. R.; BUTMAN, C. A. Animal-sediment relationships revisited: cause versus effect. Oceanography and Marine Biology, v. 32, p. 111-177, 1994.

STRAIN, L. An SDI model to include the marine environment. 2008. 134f. Dissertação (Mestrado em Engenharia de Geomática) - Universidade de Melbourne, Melbourne, 2008.

STRAIN, L.; RAJABIFARD, A.; WILLIAMSON, I. P. Spatial data infrastructure to facilitate coastal zone management. In: COASTAL ZONE ASIA PACIFIC CONFERENCE. Proceedings... Brisbane: CZAP, 2004.

TOMMASI, L. R. Consideração ecológica sobre o sistema estuarino de Santos, Estado de São Paulo. 1979. 489f. Tese (Livre Docência) - Instituto Oceanográfico, Universidade de São Paulo, São Paulo, 1979.

UNITED NATIONS ATLAS OF OCEANS. Universal atlas of the oceans. 2011. Apresenta textos, mapas, bancos de dados, etc. referentes ao tema costeiro e oceânico. Disponível em: 〈http://www.oceansatlas.org>. Acesso em: 27 jan. 2011.

UNITED STATES COMMISSION ON OCEAN POLICY. Developing a national ocean policy: Mid-term report of the U. S. Commission on Ocean Policy. 2002. Disponível em: <http://www.oceancommission.gov/documents/midterm_report/midterm_report. html>. Acesso em: 18 ago. 2011.

VACCARI, L.; SHVAIKO P.; MARCHESE, M. An emergent semantics approach to semantic integration of geo-services and geo-metadata in Spatial Data Infrastructures. International Journal of Spatial Data Infrastructures Research, v. 3, 2008.

WARWICK, R. M. A new method for detecting pollution effects on marine macrobenthic communities. Marine Biology, v. 92, p. 557-562, 1986. http://dx.doi.org/10.1007 /BF00392515. 